\title{
Significance of Remote Sensing in Health Care Monitoring
}

\author{
Pranab Hazra, Krishnendu Ghosh, Pratiti Debsharma, Soumashis Das, Soumendu Biswas
}

\begin{abstract}
IoT based health monitoring describes the response and clarification of the data collected from the recipient through sensor from the sources like hospitals by IoT based technology. The reading which are collected by using the appropriate sensor that would help the doctor in alternative situation to observe the recipient's health. The values collected by the sensors from the recipients are equipped by the Raspberry $\mathrm{Pi} 3$ model which are further transfer to the doctor's database so that they can communicate with their patients and their family members through internet application and smartphones. By using this idea any doctor can monitor and view reports of his patient from anywhere in the world without physical appearance. The database consists of heart rate, blood pressure and pulse rate of any particular patient in an appropriate manner which can be easily understandable by the doctors. Further a camera can be installed in the Raspberry Pi for live monitoring which will be more efficient for some case and all the information are stored in the medical server as all the data are very sensitive for any research purpose. This medical data is accessible from anywhere in the world using internet and providing exact IP address. For any instance if the patient's data is outstrips the normalized value it will turned an emergency alarm on for assistance. The main agenda is to provide a better treatment by regular monitoring, which will increase the standard of diagnosis and provide accurate care to the patient.

Keywords: Internet of Things (IoT), Patient Monitoring, Heart beat Sensor, Blood Pressure Sensor and emergency alert.
\end{abstract}

\section{INTRODUCTION}

The development of Internet of things is growing significantly in social, technical and economic aspects. Processors, sensors and microcontrollers along with other accessories are used for the communication and interaction of the users with each other over the internet created by a suitable protocol which has become a crucial part of Internet of Things. Gradually Internet of Things is becoming a hot cake and one of its most crucial field associated is healthcare.

Revised Manuscript Received on March 16, 2020.

* Correspondence Author

Pranab Hazra*, ECE, Narula Institute of technology, Kolkata, India, Email:pranabhazra2007@gmail.com

Krishnendu Ghosh, ECE, Narula Institute of technology, Kolkata, India, Email:gkrishnendu123@gmail.com

Pratiti Debsharma, ECE, Narula Institute of technology, Kolkata, India, Email:pratiti.debsharma@gmail.com

Soumashis Das, ECE, Narula Institute of technology, Kolkata, India, Email:dassoumashis@gmail.com

Soumendu Biswas, ECE, Narula Institute of technology, Kolkata, India, Email:biswas98soumendu@gmail.com

(C) The Authors. Published by Blue Eyes Intelligence Engineering and Sciences Publication (BEIESP). This is an open access article under the CC BY-NC-ND license (http://creativecommons.org/licenses/by-nc-nd/4.0/)
It is hence reducing the difficulties faced by the doctors to monitor all of their patients on a regular basis. Not only IOT is escalating gradually to subsidize economically and working for the betterment of the quality of patients' life but also with a proper medication it has become possible to ensure the patients' lifespan. IOT can be useful in solving the health problems which are not detected, consequently it ensures certain healthcare services and keeps a record of the identity of the patients digitally and the complications can reduced to a higher percent [1]. The whole method is of lower cost and of less complications. This is because the sensors can transmit data over computer or smartphones as well as with the host server. The sensor is used to access the pulse rate or heart rate. To ensure medical personnel with the help of GPS, GSM and web technologies, the system communicates with the server in case of accidental behavior. It is so done to attain a quick action to save the life of the patient in such condition [2]. The HTML site is connected to the system via an IP address, where the patient or the doctor can find the data's available. Thus a constant supervision of the patient is done [3]. Consequently the healthcare staff can look after patient by monitoring the server at real-time and each patients individually at a time. As long as the server is linked and the network is suitable, the system can be used to reach any sensor attached to the patient. A set of sensors collected the information of the body parameters from the patient and puts it on the server. The assembled data is further assessed for the supervision of the condition of the patient individually by the medical team [4].

\section{PROCEDURE DISCUSSION}

In this project, the raspberry $\mathrm{Pi}$ module is used as a data collector as well as processing it [5] [6].The system consists of many sensors which are connected to the patient's body and the data can be collected and processed [7]. The system for monitoring this data are the doctor's and the patient's smartphones or computer [8]. The sensors are used to fetch the data and the readings are then converted into signal. In the IoT module, these signals are provided for processing in the Raspberry Pi. The Pi displays information on a monitor [9]. The information is stored over the cloud. The doctor can access this information on his phone or computer. In case of any emergency, an automatic alert is sent through mail to the patient for medical medication. To the GPIO pin the sensors are connected and the data is transported to the host. Here, the data can be monitored by the patient as well [10] [11]. When the different kinds of sensors such as pulse rate sensor or blood pressure sensor is used, 


\section{Significance of Remote Sensing in Health Care Monitoring}

we can obtain the digital output on the monitor through the $\mathrm{Pi}$. Here the IP address of the raspberry $\mathrm{Pi}$ and the server is identical. Due to this identical address the data can be fetched and analyzed anywhere and anytime by both doctor and the patient. This data can also be stored for future references [12].

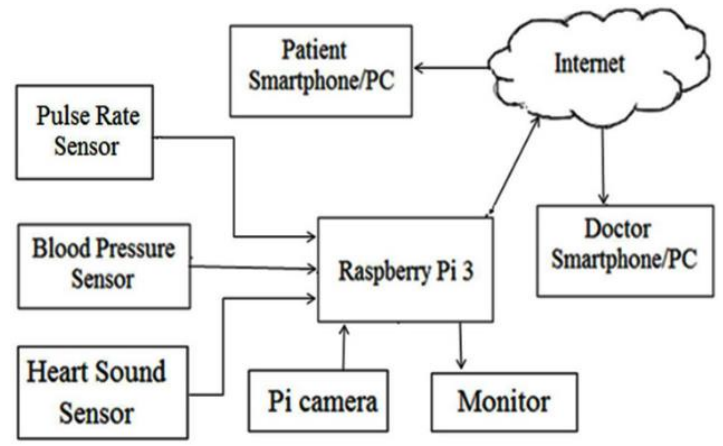

FIG: WORKING DIAGRAM OF THE PROJECT

\section{A. Raspberry PI 3:}

Raspberry $\mathrm{Pi}$ is a small pocket friendly module, it is like a small card sized computer that can used as a CPU which connects monitor, mouse and keyboard [14]. It is a 64 bit quad processor which has 14 GPIO pins, EPROM readout which supports HAT expansion boards, also has Wi-Fi and Bluetooth support on board [19]. A picture of the Raspberry Pi computer board is shown in the fig below.

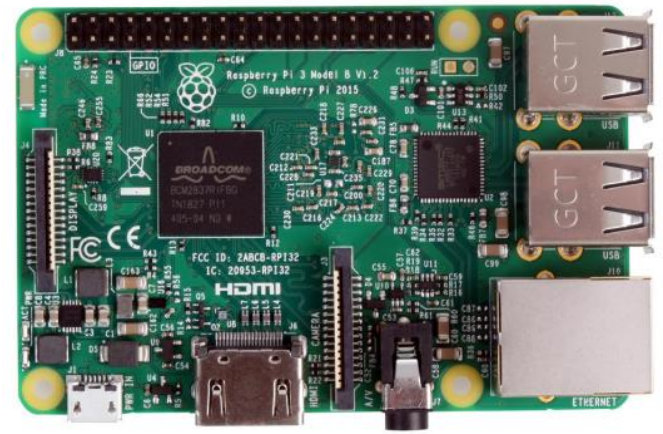

Fig: Raspberry Pi 3

\section{B. Pulse Rate Sensor:}

Pulse Sensor is a heart-rate sensor used for Arduino. It is like a plug and play module like Lego parts. It can be used by bio-makers, athletes, students, developers who want to incorporate heart rate data into their research or projects. It also has an app which is open source for monitoring the pulse rate and graph in real time. This sensor is small as fingertip [20]. The pictorial form of the pulse sensor is shown below.

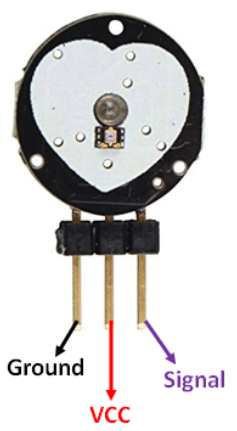

Fig:Pulse Rate Sensor

\section{Blood Pressure Sensor:}

Blood Pressure Sensor is a sensor which is used to measure the blood pressure using the non-invasive method. It is similar to sphygmomanometer but instead of the mercury column, the reading of the blood pressure taken using a pressure sensor.

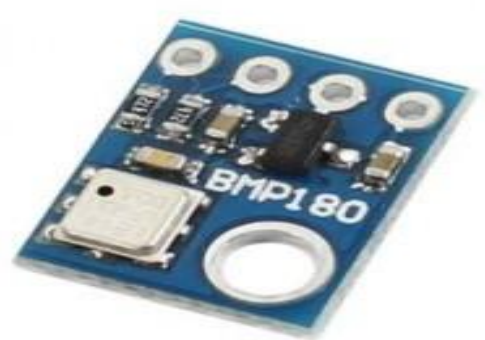

Fig:Blood Pressure Sensor

\section{Heart Sound Sensor:}

The Heart-Sound sensor has a micro-sound components which is made of with polymer materials that can gives the output as a low impedance audio signal. It is widely used in various types of equipment, such as fetal audio signal acquisition, surface-tone signal acquisition and heart sound signal acquisition.

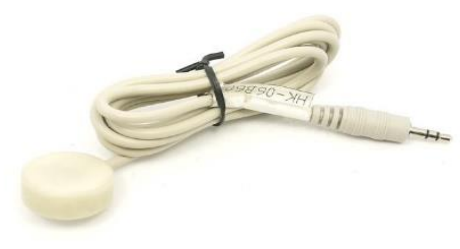

Fig: Heart Sound Sensor

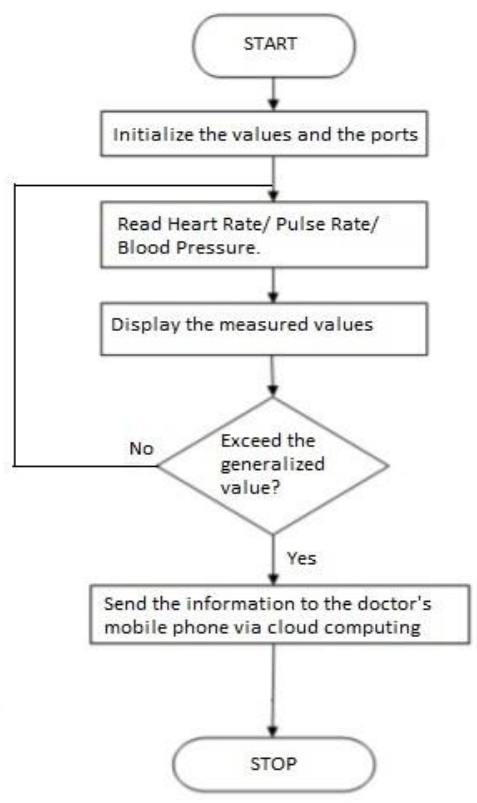

Fig: Flow chart of the working

Published By:

Blue Eyes Intelligence Engineering

\& Sciences Publication

323 (c) Copvriaht: All riahts reserved. 


\section{RESULT \& CONCLUSION}

This initiative of IoT based system gives better and effective health monitoring and care service to the required patients and the database is worldwide available through internet. Doctors can use this database for a effective and quick response and provide a thoughtful solution. By using this technique doctor can monitor their patients from anywhere at any time. An emergency alert system is introduced which provide an email as well as SMS to the patient if the normalized or threshold value is exceeded that refer they need to consult their doctor in a meantime. This is a gem for paralyzed or bed rest patient where their doctors can monitored them without physical appearance and give them precautions and assistance by visual and audio with the help of integrated Pi camera which is used in the modification. This is now implemented for one to one access only, in future in will be implemented for many by providing unique id for log in for different patients and doctors. We are also planning for an automatic ambulance call for better safety of life.

\section{REFERENCES}

1. Z. Zhiao, Chnaowei, z. Nakdahira, "Healthcare application based on Internet of Things," Proc. IEET Int. ConfE. on. Technolgy. Application. Nov. 2013.

2. Kortoom, , Y. Kaiseer, N. Fittop, and D. Ramamoorthy, "Canny matters as construction brickss for application of Internet of Things," IEEE Internet Networks and Comput., vol. 17.

3. Sunehra and P. Ramakrishna, "Web based patient health monitoring system using Raspberry Pi," 2016 2nd International Conference on Contemporary Computing and Informatics (IC3I), Noida, 2016, pp. 568-574.

4. S.V. Manikanthan , T. Padmapriya "An enhanced distributed evolved node-b architecture in 5G telecommunications network" International Journal of Engineering \& Technology (UAE), Vol 7 Issues No(2.8) (2018) 248-254.March2018.

5. Ingole, S. Ambatkar and S. Kakde, "Implementation of health-care monitoring system using Raspberry Pi," 2015 International Conference on Communications and Signal Processing (ICCSP), Melmaruvathur, 2015, pp. 1083-1086.

6. D. McDuff, S. Gontarek and R. Picard, "Remote Measurement of Cognitive Stress via Heart Rate Variability," in 36th Annual International Conference of the IEEE on Engineering in Medicine and Biology Society , 2014.Y.

7. Kumar, S.S., Kumar, Dr. K.A.: Neural networks in medical and healthcare. Int. J. Innovative Res. Develop. 2(8), 241-244 (2013).

8. R. Kumar and M. P. Rajasekaran, "An IoT based patient monitoring system using raspberry $\mathrm{Pi}, " 2016$ International Conference on Computing Technologies and Intelligent Data Engineering (ICCTIDE'16), Kovilpatti, 2016, pp. 1-4.

9. www.raspberrypi.org/documentation/usage/

10. Sang-Joong Jung, RistoMyllylä, and Wan-Young Chung, "Wireless Machine-to-Machine Healthcare Solution Using Android Mobile Devices in Global Networks",Member, IEEE,IEEE SENSORS JOURNAL, VOL. 13, NO. 5, MAY 2013.

11. J. G. Ko, C. Y. Lu, M. B. Srivastava, J. A. Stankovic, A. Terzis, and M. Welsh, "Wireless sensor networks for healthcare", Proc. IEEE, vol. 98, no. 11, pp. 1947-1960, Nov. 2010.

12. M. S. D. Gupta, V. Patchava and V. Menezes, "Healthcare based on IoT using Raspberry $\mathrm{Pi}, " 2015$ International Conference on Green Computing and Internet of Things (ICGCIoT), Noida, 2015, pp. 796-799.

13. Hassanalieragh, M., Page, A., Soyata, T., Sharma, G., Aktas, M., Mateos, G., Kantarci, B., Andreescu, S.: Health monitoring and management using Internet-of-Things (IoT) sensing with cloud-based processing: opportunities and challenges. In: IEEE International Conference on Services Computing, pp. 285-292 (2015)

14. K. Navya, Dr. M. B. R. Murthy, "A Zigbee Based Patient Health Monitoring System", Int. Journal of Engineering Research and Applications Vol. 3, Issue 5, Sep-Oct 2013, pp.483-486.

15. Swamy G., Kodali R. K., and Lakshmi B. "An Implementation of IoT for Healthcare", IEEE Recent Advances in Intelligent Computational Systems (RAICS) 10-12 December 2015.
16. Gupta P., Agrawal D., Chhabra J., Dhir P. K. "IoT based Smart HealthCare Kit", Jaypee University of Information Technology, International Conference on Computational Techniques in Information and Communication Technologies (ICT ICT), 2016.

17. Thirumala settee Sivakanthand S. Kolangiammal, "Design of IoT Based Smart Health Monitoring and Alert System", I J C T A, 9(15), 2016, pp. 7655-7661.

18. Tiwari, A., Gautam, A.: Classification of Mammograms using Sigmoidal Transformation and SVM. In: Proceedings of International Conference on Smart Computing and Informatics (SCI-2017), pp. 1-8, March 2017

19. Murray A., and Khambete N. D. "National efforts to improve healthcare technology management and medical device safety in India," 7th International Conference on, IET, pp. 1-5, 2012

20. Pardeshi, S. Sagar, S. Murmurwar And P. Hage, "Health Monitoring Systems Using Iot And Raspberry Pi — A Review," 2017 International Conference On Innovative Mechanisms For Industry Applications (Icimia), Bangalore, 2017, Pp. 134-137.

\section{AUTHORS PROFILE}

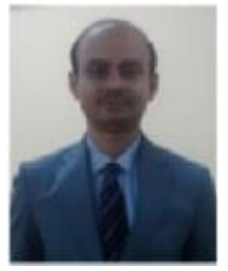

Pranab Hazra, is working as Assistant Professor in the department of Electronics and Communication Engineering, Narula Institute of Technology. He has the research interest in Steric signal analysis, Radon anomalies before seismic activity through remote sensing and GIS and Signal Processing. He has six numbers of publication in international journal and one in Natural journal except these, he also published some research work in internal and national conference. He also has a book chapter as well as he is one of the editor of the book namely "Advanced Computation on Electronics and Remote Sensing". He received M.Tech. From Institute of Radio physics and Electronics, University of Calcutta. He is pursuing Ph.D. at Institute of Radio physics and Electronics, University of Calcutta. He was achieved the best paper award in International Conference on Computational Advancement in Communication Circuit and System-2018.

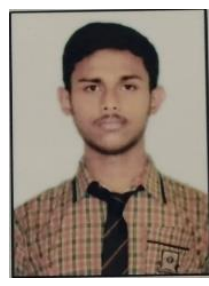

Krishnendu Ghosh, Currently pursing btech 3rd year, from Narula Institute of Technology, with an average cgpa of 8.63, and a member of yuva,

Presented a paper titled "Footstep power generation by piezoelectric effect" in the national conference on science, Presented paper titled "baseline correction algorithm-survey" jointly organized by ieee cas kolkata section and IEEE cas student branch chapter,nit,on 3rd may 2019.

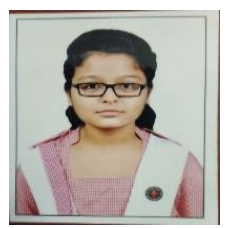

Pratiti Debsharma, Currently pursuing btech 3rd year from Narula Institute of technology, with an average cgpa of 8.83. Her research interests include Biomedical, Internet of Things (IoT)

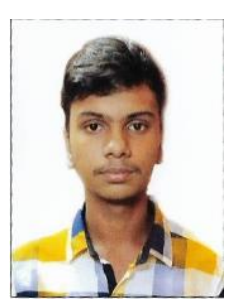

Soumashis Das, Currently pursuing btech 3rd yea from Narula Institute of technology, with an average cgpa of 8.78,A member of Yuva. Presented a paper titled, "Footstep power generation by piezoelectric effect" in the national conference of science. Presented a paper titled "Study the effect of smoking on Heart Rate Variability" jointly organised by ieee cass Kolkata section and IEEE cass student branch chapter, nit on 3rd may 2019. Presented a presentation on "EOG controlled wheelchair for Quadriplegics Patients" at National Hackathon Bengalathon 2019 and became the winner.Currently doing a research work on the EOG controlled wheelchair. 
Significance of Remote Sensing in Health Care Monitoring

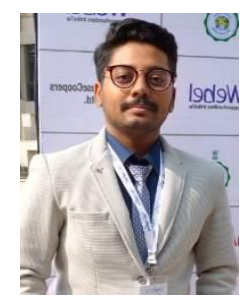

Soumendu Biswas, Currently pursuing btech 3rd year from Narula Institute of technology, with an average cgpa of 8.65,a member of Yuva. Presented a paper titled, "Footstep power generation by piezoelectric effect" in the national conference of science. Presented a paper titled "Study the effect of smoking on Heart Rate Variability" jointly organised by ieee cass Kolkata section and cass student branch chapter, nit on 3rd may 2019 and became the winner. Presented a presentation on "EOG controlled wheelchair for

Quadriplegics Patients" at National Hackathon Bengalathon 2019 and became the winner.Currently doing a research work on the EOG controlled wheelchair.

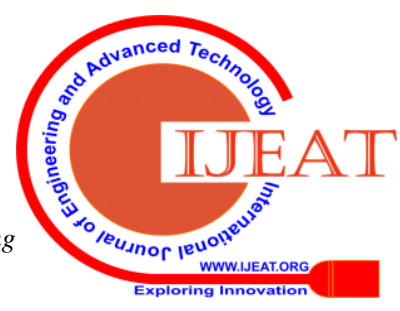

